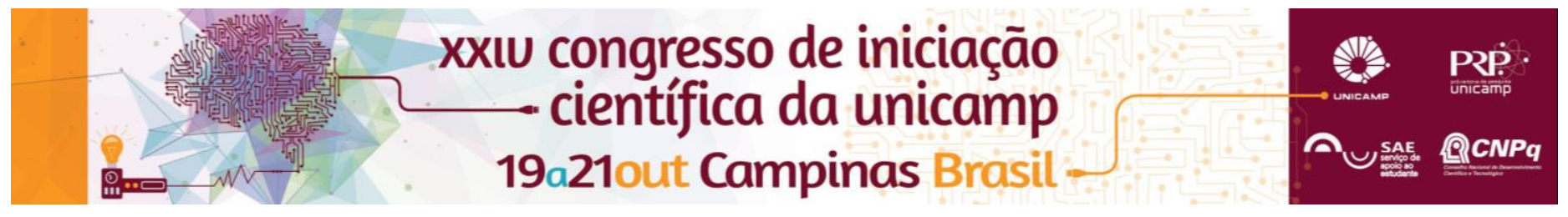

\title{
BioCad Application and Simulation in Bioengineering Problems.
}

\section{Henrique Takashi Idogava*, Pedro Yoshito Noritomi, Daniel Takanori Kemmoku}

\begin{abstract}
The reconstruction of the anatomical geometry in BioCad area enables the generation of finite element models for study of stresses and strains from biomechanics conditions. This paper aims to describe the activities in simulation of a Biological System process.
\end{abstract}

\section{Key words:}

Finite Element Analyses, BioCad, Femap.

\section{Introduction}

The model in Finite Element allows virtual observation of the biomechanical behavior of structures modeled on the computer in order to reduce the number of in vivo assays, which is critical in anatomical structures end harmful to man'.

The work done in BioCad area represent standardized anatomical structures, but preserve a certain degree of interpersonal variability. The base of methodology is the identification and selection of key anatomical landmarks, the same way that this technique is also adopted in geometric modeling engineering.

After generation of the finite element model are simulated physical phenomena model. The virtual 3D modeling and computational mechanics simulation help in the study of solutions to anatomical problems.

\section{Results and Discussion}

The work involved the STL file obtained by scanning a Molar tooth. A contact scanner was used to obtain the STL file that helps to make plans and lines for the main anatomical landmarks of the tooth. The lines set the edges of a new surface in CAD Rhinoceros (Robert McNeel \& Associates).

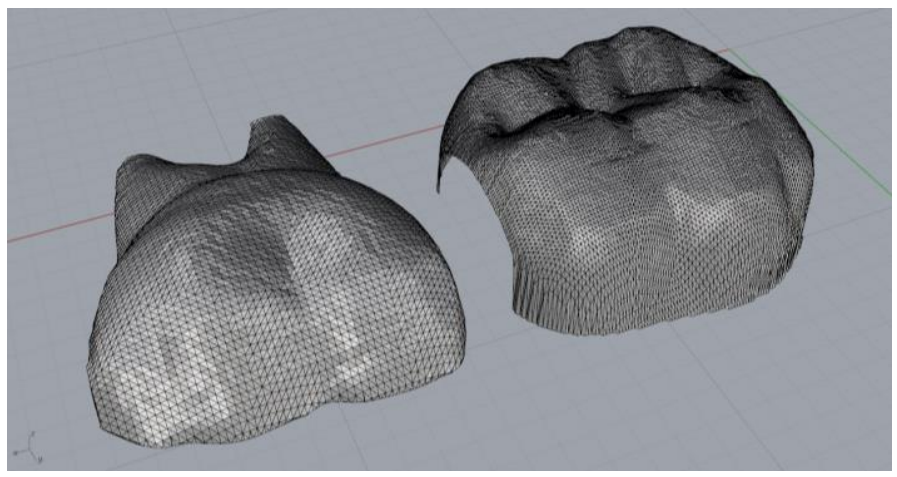

Image 1. Model in STL after 3D scanning

The new model in .parasolid format was imported into the pre and post processor Femap v10.2 (Siemens PLM Software). NEi Nastran Editor (NEi Software) simulate the conditions after set the properties of isotropic material, contact regions, constraints and loads in Femap. The maximum stress and displacement analysis showed the most required regions in a qualitative way.

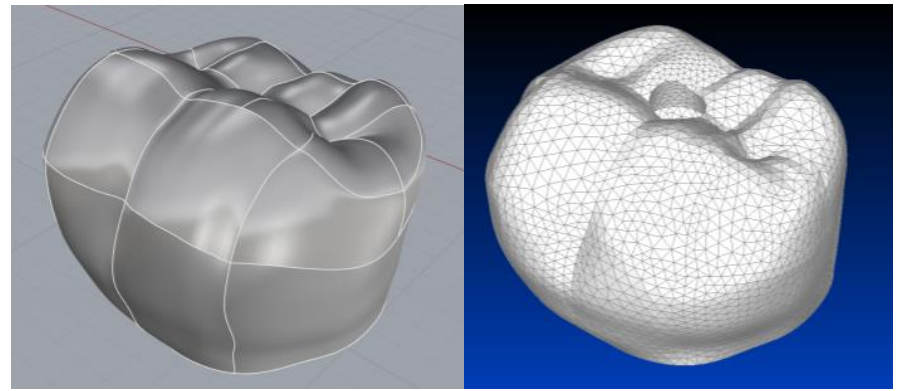

Image 2. Model in CAD and Finite Element Mesh

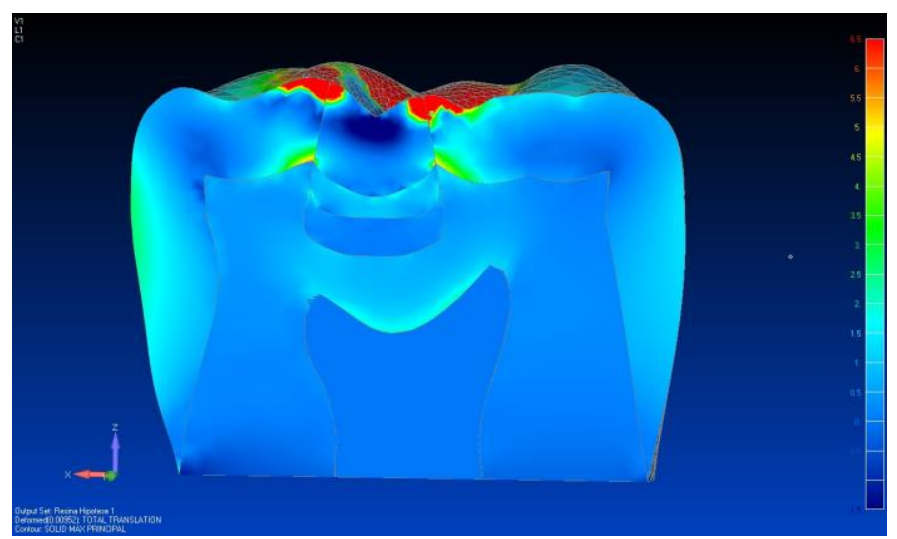

Image 3. Analysis of Maximum Stress

\section{Conclusions}

Analyzes of fractures, strain, displacement and stress in odontology are examples of BioCad applications in bioengineering problems. Contact to the healthcare professional with the engineering is very important to establish the actual conditions to validate the model tested.

\section{Acknowledgement}

I would like to thank Professor Pedro Noritomi for the opportunity in CTI Renato Archer, the colleague Daniel Kemmoku by training and qualification, the team DT3D, $\mathrm{CNPq}$ and Unicamp for academic improvement.

${ }^{1}$ Freire, Diego. Testes em animais são reduzidos com novos ensaios in vitro e simulações. Agência FAPESP, 06 de abril de 2015, Disponível em: http://agencia.fapesp.br/testes em animais sao reduzidos_com novos ens aios_in_vitro_e_simulacoes/20928/ Acessado em 05 de Julho de 2016. 